\title{
The role of teams in the competence development process
}

\author{
Lars Schweizer* \\ University of Frankfurt, \\ Grüneburgplatz1. 13, \\ D-60323 Frankfurt am Main, Germany \\ Fax: (+49) 69-798-3-530 \\ E-mail: 1.schweizer@em.uni-frankfurt.de \\ *Corresponding author
}

\section{Mirjam Geiger}

das talentbuero,

Hopfengartenstr. 1, D-63457 Hanau, Germany

E-mail:mg@talentbuero.de

\begin{abstract}
Teamwork and competence development are two issues of growing interest in knowledge-intensive organisations, especially in dynamic high-tech sectors. So far, existing literature has not addressed the role teams play in the development of competences that are crucial to the individual organisation member. Therefore, we chose the high-tech sector, in which teams are the predominant form of job design, to conduct an exploratory case study of the competence development process at Microsoft Germany. Our research results show that in a fast-paced environment, teams can provide an adequate learning context and environment for specific competences, as long as they are purposefully integrated in an individual competence development process, contributing to the development of individual competences like problem solving, building team spirit and self-development.
\end{abstract}

Keywords: teams; teamwork; competence; competence development process; high-tech sector.

Reference to this paper should be made as follows: Schweizer, L. and Geiger, M. (2011) 'The role of teams in the competence development process', Int. J. Management Development, Vol. 1, No. 1, pp.60-78.

Biographical notes: Lars Schweizer holds the UBS-endowed Professorship for Management at the Johann-Wolfgang-Goethe University in Frankfurt, Germany. $\mathrm{He}$ is a Visiting Professor at Grenoble Ecole de Management in France. His research interests are in strategic management and M\&A.

Mirjam Geiger holds a Masters degree from the University of Bamberg and is currently a Consultant and Trainer for das talentbuero. 


\section{Introduction: the necessity for competence development}

In today's changing and competitive environment, companies need employees that are able to take the initiative, cooperate beyond departmental borders, establish intensive communication, and solve problems independently. In knowledge-based companies, employees must usually demonstrate these competences in teamwork. However, there is a lack of research on how to capitalise on the potential synergies that teams offer (Salas, Burke et al., 2000), and on the impact of team processes on the competence development of the individual team member.

Most of the work done so far has analysed the behaviour and mechanism of small groups. The group dynamics research analyses, from a psychological perspective, the effectiveness of small groups and teams. It provides important findings concerning various aspects of the functioning of teams, particularly such factors as, group composition or group size, both of which influence the performance of the team, and the satisfaction of the team members (McGrath, 1984; Sader, 1991; Witte and Davis, 1994).

Given their knowledge of the motives and needs of individual human beings in connection with work in organisations, researchers in the field of work and organisational psychology have analysed the development of different work concepts (Antoni, 1996; Frese and Zapf, 1994; Hacker, 1986; Hackman and Oldham, 1980). Newer concepts, such as change management and organisational development, provide managers with orientation and recommendations concerning the introduction of team-oriented structures and at the same time keep in mind the company's goals (French and Bell, 1994).

The contribution of teams to firm performance was examined, in particular, from an organisational theory perspective by developing a variety of concepts (Unger, 2002). The competence-oriented view (Hamann and Freiling, 2000; Lado et al., 1992) such as the well-known core competence concept of Prahalad and Hamel (1990) can be regarded as a further development of the early resource-orientated perspective in the strategic management literature (Barney, 1991; Wernerfelt, 1984). Concepts such as the learning organisation, or knowledge management, consider teams as catalysts for the development of specific core competences, in order to provide a basis for long-term competitive advantage and the success of the company (Foster et al., 1995; Senge, 1990).

There are numerous overlaps between these different research streams. However, the existing literature lacks an integrating perspective that analyses how teams in organisations contribute to the competence development of the individual team member, of the team in comparison to other teams, and of the entire organisation. It is important to analyse and understand the relationship between the individual and team competence development as both are necessary and important for the future success of the company. This exploratory paper aims at describing how individual and team competence development processes are linked with one another. As a result, researchers as well as practitioners can gain some starting points for the design of follow-up studies, on the one hand, and for the conception and implementation of competence development tools and processes in companies, on the other hand.

Our research will concentrate on the analysis of the role and contribution of teams to the competence development of individual organisational members by linking competence development and learning. Findings from learning psychology form the 
theoretical basis for our analysis. After a discussion of the term 'competence' a theoretical part follows. In this part, we discuss the requirements and opportunities of teamwork from a learn-theoretical perspective. Then, we present the research design of our case study. Following that, the research results are described in more detail, and, based on the recommendation of Eisenhardt (1989) confronted with existing theory, to present conclusions regarding the use of teams during the competence development process. Finally, the implications and limitations of the research work are discussed, and areas for further research are identified.

\section{Theoretical foundation}

\subsection{The meaning of 'competence'}

So far there is no uniform understanding of the competence construct. From an etymological point of view, today's word 'competence' stems from the two Latin expressions 'com' (together) and 'petere' (first vines, to reach search). Chomsky (1980) introduced the term into communication science, to designate the ability to communicate effectively in a certain language. His study reveals that competence is an invisible combination of different components, which are organised in such a way that a specific achievement results in concrete situations (Weinert, 2001).

White (1959), who introduced the term competence to motivational psychology, stresses that competences are a necessary prerequisite for successful acting (performanz) in certain situations, but they are not genetically innate. Competences result from the individual development process: they emerge in the interaction between the individual and its environment (Erpenbeck and von Rosenstiel, 2003). McClelland (1973) states that competences can only be analysed on the basis of observable behaviour. From this point of view, competence is only the result of some form of judging (attribution), which an observer attributes to an action.

On the basis of the characteristics discussed above (subject focus, action orientation, situation dependency, and capability of development), Erpenbeck and von Rosenstiel (2003) define competence as the internal conditions for the regularisation of an action at a certain time. The assumptions of this (broad) working definition provide the basis for the selection and the interpretation of the literature that we discuss in the following sections. Thus, we take a very broad perspective of competence that comprises expertise, knowledge, and skill, as well as ability, and reflects the overall exploratory nature of our study.

\subsection{Basics of the competence development process}

Individual competences can be considered as a prerequisite for the preservation and further development of core competences as individual competences form the foundation for the development of organisational capabilities (Barney, 1991). As we are interested in the development and organisation of the competence development process itself, a theoretical understanding of how human beings acquire competences is necessary. 


\subsubsection{Learning theories}

For a long time, the classical understanding of learning in psychology was influenced by the deterministic view of behaviourism and neo-behaviourism. Humans were regarded as organisms that respond to particular stimuli. However, this research direction neglects the cognitive and the motivational components of learning (Piaget, 1948). Therefore, these theories are not able to sufficiently explain the development of competences. Thus, other explanations of learning must be considered, in order to explain learning as a prerequisite of competence development.

From Banduras' (1979) social-cognitive learning theory, which is complementary to the work of Vygotsky (1978), it is well known that humans learn not only from their own experiences, but also at the model, i.e., by observation of others in a concrete situation. Employees are able to learn from their co-team workers by observing how they solve a certain problem. Moreover, mentoring and coaching is possible. In this context, employees can discuss certain issues concerning their future career and the respective competences they have to build up with their mentor or they coach - who at the same time can serve with their behaviour and competences as a model for the employee she or he mentors or coaches.

Kolbs' (1984) theory of the experience learning postulates that learning is always associated with a specific situation or context. Knowledge has not only a social component, but also an individual one, since it is the result of interaction between the individual and its respective environment and, thus, continually changes (Unger, 2002). Experience learning takes place via reflection, which can be initiated either by the individual or from outside in the form of feedback during mentoring or coaching. Similar to that, Reynolds and Vince (2004) reconstruct experience-based learning as a practical reflexivity involving an intuitive, tacit sense and an explicit understanding of complex situations.

Senge (1990) speaks of learning as a change of mental models. Mental models mark the often unconscious faith sets that affect and determine both the action and the cognition of humans. Mental models are internal representations of knowledge, which humans use to interpret specific situations (Seel, 1991). They represent modes of evaluating reality: however, they have only a simplifying character, and help to reduce complexity. The usefulness of mental models is closely connected with their correctness and their suitability to the situation.

The recognition of inadequate mental models is only possible in a concrete social context, because mental models can only be understood by means of communication, regarded as indication-obtaining interaction between communication partners (Seel, 1991). That is, certain forms of communication between two or more individuals provide the possibility of recognising and examining the correctness and suitability of mental models. Learning takes place when the existing mental model is replaced by a new one, which then form the basis for further acting. This change contains the acceptance and internalisation of new values, and the construction of a new mental model.

As far as teams are concerned, Mathieu et al. (2000) have shown that shared-teambased and task-based mental models are positively related to subsequent team process and performance. In a further study, Mathieu et al. (2005) demonstrated that team processes and performance were better in teams sharing higher-quality team mental models than in teams evidencing less sharing, or that had lower-quality models. 


\subsubsection{Competence via self-organisational learning}

The concept of self-organisational learning is based on constructivism. The core assumption of constructivism is that reality is always a reality designed by the individual itself (von Glasersfeld, 1987, Luhmann, 1990). This contradicts the deterministic view that characterises the traditional understanding of psychological learning. In addition, radical constructivist theories emphasise the mental processes of individual learning, and neglect situational factors, which are able to initiate and to affect learning. Therefore, learning theories based on moderate constructivism recognise that learning usually takes place together with others, in the appropriate social environment. Thus, learning is understood as a constructional, emotional, social, situational, self-steered, and active process.

According to Erpenbeck (1997), the appropriation of competences can be described as an organised internalisation process, from value attitudes to emotions and motivations that result in actions. This process can be arranged during training-like education processes, or facilitated by moderators: however, a self-organised learning of competences is always required. That is, the appropriation of action competence is to be equated with self-organised learning processes (Greif and Kurtz, 1998).

Learning is self-organised if a system (group, organisation, company) enters into work situations that cannot be mastered with the existing competences. The aim of this self-organised learning is to extend and deepen the capabilities of the system (Erpenbeck, 1997). Nonetheless, this happens only if an appropriate self-learning competence is present.

A prerequisite for self-organised learning is self-learning competence, which is affected by cognitive, motivational, and situational aspects. According to Straka and Stöckl (2001), the development of self-learning competence depends on the degree to which humans perceive autonomy, self-effectiveness, and social integration. These three conditions are represented by the concept of the 'scope of action' (Baitsch, 1985). This concept states that the more autonomous and the more positive the self and foreign estimates of competence existed in past roles, the more the individual is ready to take over responsibility for further competence development processes and self-organised learning.

The team is an ideal work organisation form that creates a large scope of action, and thus strengthens self-learning competence, and promotes self-organised learning optimally (Antoni, 1996; Unger, 2002). According to Parker (1990), a team is understood as a group of people that interdependently pursue a common goal or task. Moreover, groups fulfil a further precondition of self-organised learning, by favouring the recognition of contradictions. Following Baitsch (1985), contradictions are considered as a starting point for competence development, because they represent a discrepancy between a desired condition and the actual perception of reality. This discrepancy can be both task-conditioned and interaction-conditioned: it can arise within the system under consideration (here, the team), and between the system and its environment (between team and management). If a team confronts itself consciously with these discrepancies by reflection and dialogue, then the individual team member learns not only during the complex task and during the approach to the solution of this task, but also during interaction in the team and during the process of learning.

Following this theoretical argumentation, teams can, under certain conditions, positively affect the development of individual competences, by providing the necessary 
learning environment. Whether these conditions are given in practice, and to what extent teams thereby take an important role, will be illustrated using the example of the subsequent case study.

\section{Methodology}

Since very little is known about the role and contribution of teams in the individual competence development process, a thoroughly detailed and, more specifically, qualitative approach is called for. According to Yin (1984), Lee (1999), Glaser and Strauss (1967), and Miles and Huberman (1994), case study analysis should be applied if a 'how' or 'why' question is asked about a current phenomenon that must be examined in its current context, using a multiplicity of data sources. Kepper (1996) points out that a single case study is a useful and meaningful proceeding when a qualitative objective is to be examined. We focus on Microsoft (Eisenhardt, 1989; Yin, 1984) for the following reasons.

The high discrepancy between the evaluation of its material assets and the stock market valuation of Microsoft reflects the high value of its immaterial assets, making Microsoft a typical company of the information and knowledge age. It is known that high complexity and the dynamic nature of the information technology industry require high individual technical skills, along with a team orientation and the readiness to be flexible (Cusumano and Selby, 1996). In view of such large challenges, above-average employee satisfaction was the basis on which the German business magazine Capital awarded Microsoft 'Best Employer 2003' in Germany. Furthermore, Microsoft was nominated for the 'Lifelong Learning Award' of the European Commission. All this makes Microsoft some sort of 'unique' case. Microsoft is not only successful in financial terms, but also when considering working conditions and employee satisfaction. Thus, Microsoft can be considered as some kind of 'good practice' case in the high-technology sector, making it worthwhile to analyse this case.

Moreover, we became interested in the topic of competence development by a lecture entitled 'Employee Training and Partnering' given in September 2002 by Ashley Wheaton, the former Director of Learning Services at Microsoft, at a symposium in Munich (Wheaton, 2002). Another opportunity to contact a top manager from the Munich office resulted after another lecture given at a Bavarian University. He also confirmed the actuality and importance of this topic at Microsoft. Furthermore, we contacted a human resource manager who is strongly involved in the process of competence development. Thus, it became possible to analyse a topic on which no research exists in the literature. The major aim of this exploratory study is to describe the competence development process of Microsoft at the example of Microsoft Germany along with the different methods and tools applied and to establish a link between the individual and organisational competences and how the team-oriented working approach at Microsoft Germany is related to the individual competence development process. The central research questions of this study are as follows: How does the team-oriented competence development process take place at Microsoft Germany? What methods and concepts are used in this process? What experiences has Microsoft Germany gained with this process?

In addition to the two lectures, we have carried out three interviews with members from the management board, the director of the personnel department and a team member, covering different perspectives and different hierarchical levels in the 
organisation. Moreover, we used available literature, information taken from websites, press releases, presentations, and internal documents for our case analysis in order to triangulate the data (Jick, 1979). This study uses the problem-centred interview as a form of the explorative, semi-structured interview. Since the research questions themselves are very broad, an interviewer manual was developed, with the help of a literature analysis (e.g., Erpenbeck and von Rosenstiel, 2003; Hamann and Freiling, 2000; Lado et al., 1992), to define some more specific questions. The interviews with the company representatives from Microsoft employed a semi-structured design, to allow for an appropriate degree of comparability, and to provide ample opportunity for an unobstructed flow of narrations. The semi-structured interview design included the following questions:

1 How do you define competence?

2 What competences are relevant to the company and why are they relevant?

3 What methods are used to develop and foster competences?

4 What role does teamwork play?

5 How is teamwork related to the relevant competences?

6 What relationship exists between individual and team competences?

The first part of the data analysis consisted in transcribing the fully taped interviews. Based on cyclic reading and rereading, each interview was structured and coded in order to facilitate subsequent analysis. The evaluation and interpretation of the interview data took place according to the procedure of qualitative content analysis, according to Mayring (1993) and was carried out by the two authors of the study. The developed coding manual defines categories for the questions, which were taken from the interview manual; it also states anchor examples, and specifies coding rules. The different categories are used to depict the methods and tools of the competence development process at Microsoft. In the following section, we describe the results of our exploratory case study.

\section{Findings of the case analysis}

\subsection{The idea of competences at Microsoft}

At Microsoft, the importance of competence development has increased in recent years, and it is one of the top topics at management level. Moreover, the process of competence development is part of the strategic and operational goals at Microsoft. A very good example of this is the so-called competency tool kit (CTK), which was developed in 1995, and is based on a survey questioning managers. In this context, seven success factors (cf. also Figure 1) of the company were identified: results, customer feedback, teamwork, long-term approach, passion for products and technology, functional/technical knowledge/skills, and individual excellence.

The success factors are based on specific competences, which are directly assigned to them. "Competencies enable employees to do the job" was the understanding of competences, as expressed in the interviews. This corresponds fairly well with our broad 
working definition of competence, introduced at the beginning of the paper. Thus, management at Microsoft operates in the awareness that the competences of its employees secure the success of the company. Thus, competences are inseparably connected with individual performance, and must somehow be evaluated. They are regarded, not as constant personality characteristics, but rather as 'abilities' that can be acquired and improved through learning. This indicates the potential for development supported by different instruments and methods.

Figure 1 Success factors of Microsoft

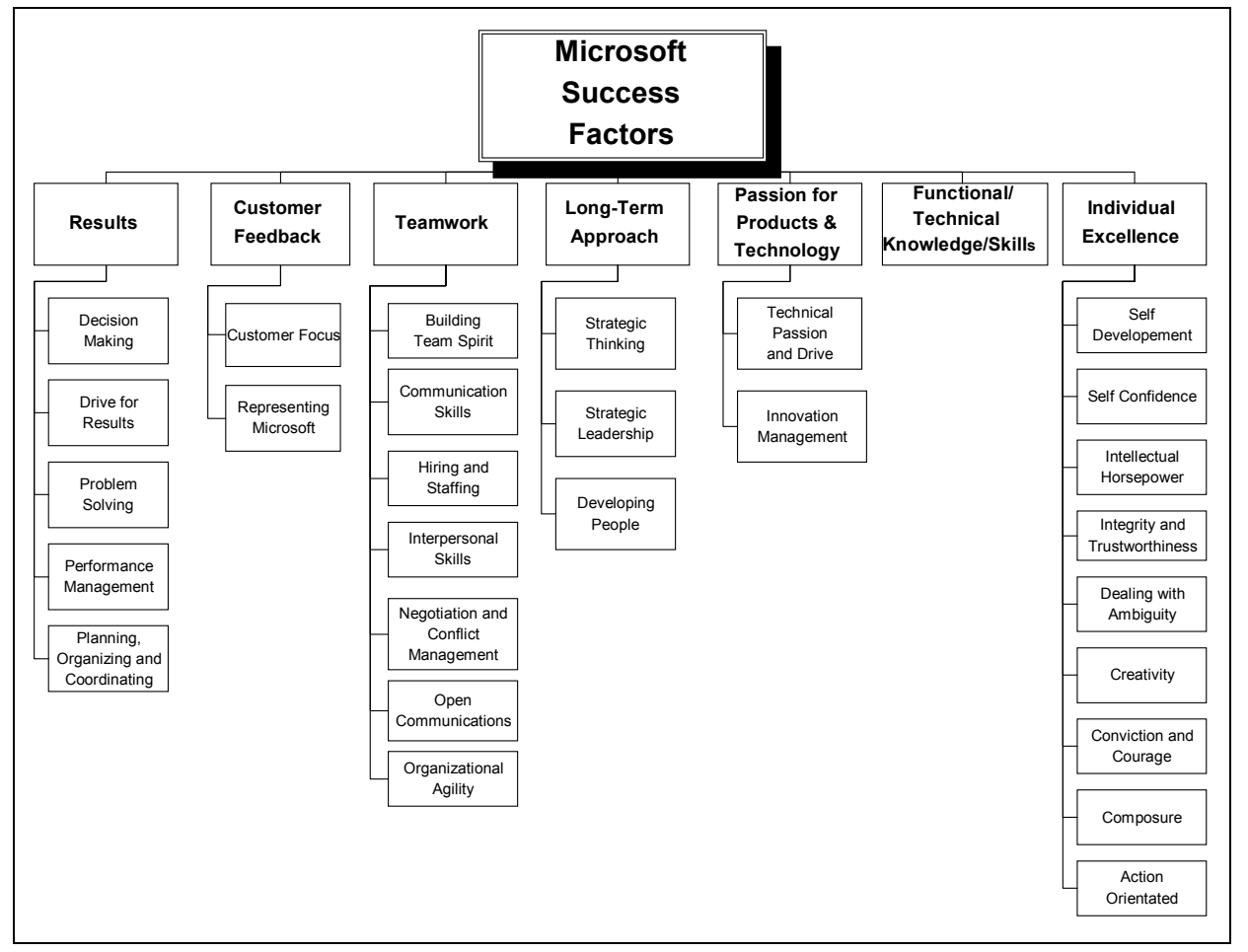

\subsection{The process of competence development}

In order to understand the role and contribution of teams to the development of competences, it is first necessary to describe the entire process of competence development that Microsoft employs, along with the different methods and tools used.

Analysis of current competence condition (actual analysis). Competences are developed only through the combination of action and reflection. It is possible to foster this development in situations that make excessive demands on the existing competences of an organisation member, e.g., when he or she, for the first time, leads a complex project as a project manager. To be able to cope with this excessive demand, and understand it as a learning opportunity, it is necessary to provide opportunities for dialogue and reflection. Reflection makes it possible to recognise contradictions in the current situation, to promote the analysis of personal goals, and to use a qualitative selfassessment of consciousness to develop existing competences. 
For this purpose, Microsoft uses the CTK. It is a competence classification system that can be used to determine current competences: in each case, these are assigned to one of the success factors mentioned above (cf. Figure 1), and define the potential development paths of selected competences. Competences such as, e.g., open communications, a competence of the teamwork success factor, is first generally defined, and then verbally described in four different development stages. Additionally, the competence card contains an example of the demonstration of the competence in question. The card suggests several questions to facilitate the manager's evaluation of the competence level of the individual.

Definition of goals (objectives). As long as people do not merely repeat experienced operational sequences, but learn new things, they naturally acquire particular competences. However, in the organisational context, goals need to be aligned. Individual motivation and action should reflect the company's vision and purpose, and to achieve this ideal is a fundamental managerial task.

Goals orient acting: i.e., they indicate a certain direction. At Microsoft, it is suggested that individual actions contribute to those factors that have been identified as decisive for the success of the entire company. Goals are agreed upon through dialogue. Managers and employees meet once a year for what is called the development review. Microsoft applies management by objectives, the core of which is represented by the development review. There, the personal development of the employee will be discussed, and goals for the next year will be formulated. This concerns both performance-related goals, the so-called businesses goals, and goals related to personal advancement, the so-called development goals. The latter are of special interest in the context of this paper. In the course of the development review, manager and employee discuss the competences relevant to the individual's future role and tasks, and finally agree "on five to seven competencies one will focus on and say, these are the most important ones, otherwise it becomes too broad" (interview quotation).

The selection of these competences and their appropriate qualitative level is the result of the clear communication of requirements and expectations between management and staff. From the individual's point of view, it takes a conscious decision regarding a particular role and the associated requirements. From the manager's point of view, it is important to call the employee's attention to his or her learning opportunities. Our interview partner, e.g., asks his employees to imagine their work activity as a fifty-year old. This mental scenario can help to increase consciousness of personal goals, which in turn can be transformed into vocational goals, from which again competence development goals are derived.

To give an example, a competence development target might be to reach Level 2 of the competence 'problem solving' within a year. According to the definition, an employee on the basic level of this competence is able to solve routine problems effectively, and to report problems he or she cannot solve to his or her direct supervisor. A second level-employee can solve moderately difficult problems that concern his or her group, can experiment with different solutions, can make crucial contributions to problem solution within his group, and develop solutions for slightly more complex problems. However, before putting them into practice he or she will consult a higher-level manager.

When both development and performance goals have been agreed upon, and concrete actions are planned, they are documented on the goalsheet. Of course, this tool can be used as a personal reminder. However, balancing future-oriented development goals 
against actual performance-oriented goals becomes a crucial question of personal time management and prioritisation.

\subsubsection{Forms of learning (realisation)}

The question that follows the definition of competence development goals is, in which ways are the selected competences best developed. The methods Microsoft uses can be clustered into three main categories

1 training

2 mentoring and coaching

3 learning on the job.

According to the evaluation of our interview partners, "learning ... takes place only to $10 \%$ by training, $70 \%$ on the job and to $20 \%$ by Mentoring and Coaching" (interview quotation). Thus, learning on the job is the most important way of learning at Microsoft. Nonetheless, we consider the efforts Microsoft undertakes in the other categories worth mentioning. To maintain our focus on the competence development process, we suggest the notion of learning forums that include different kinds of learning, and interactive effects concerning other learners and learning forms.

\subsubsection{Training as a learning for $(u) m$}

Via intranet, Microsoft employees can keep themselves informed of the different training opportunities. In their personal profile, they can also view their personal training record. Some trainings are directly assigned to particular competences of the CTK, while others are developed for specific competences. To participate in particular trainings, an arrangement has to be made with the manager and the personnel department. Each employee at Microsoft has 20 paid training days a year at his or her disposal. Technicians can do 10 extra days of technical training. Although trainings have an important role in the development process, the following disadvantages limit the suitability of this form of learning: long-term planning is required, a lot of time is needed, costs are high, and, often, the transfer of knowledge is lacking. Forms of learning that are more concretely related to the situation of the employee are mentoring and coaching which account for $20 \%$ of learning at Microsoft.

\subsection{Mentoring and coaching as a learning for $(u) m$}

The mentoring system is based on the fact that experienced employees pass on their knowledge, answer questions from 'inexperienced' employees, give feedback, coach them with regard to special problems, and provide support for career planning issues (Cusumano and Selby, 1996). Mentoring is central to the training of next generation managers.

Coaching is primarily a managerial task. However, it is also practiced amongst colleagues. From a leadership point of view, it means to bring "the employee there that he himself comes to an answer, because this actually increases the learning process" (interview quotation). Thus, the crucial competence is the ability to ask the correct questions. External or internal coaches assist in the analysis of certain situations and 
problems, and support the search for solutions through the planning of concrete action. The main advantage of coaches is their outside view. However, the costs of external coaches are relatively high. This is one reason why they tend to be an add-on to the third and most important learning form, which is learning on the job, which accounts for $70 \%$ of the learning at Microsoft.

\subsection{Learning on the job as a learning for(u)m: individual learning and learning in the team}

Learning on the job means that learning is merged into the everyday work life. It extends the past scope of action of the person in question in the direction of the agreed-upon goals. E.g., if someone wants to become a manager, then he or she will have to gradually take over the manager's role during goal setting or review discussions. The management aspirant may be assigned the leadership role of a project. "Here the people get big jobs and with them they grow. That is the philosophy at Microsoft. That the people get big tasks and at the big task they grow" (interview quotation). This can happen if the task exceeds the past competence condition, and thus forces the individual to leave his or her comfort zone. "You can only grow outside your comfort zone" is the basic message of this form of learning, according to our interview partner. To avoid panic, opportunities for reflection and discussion must be provided. Feedback from the accompanying manager or coach plays a crucial role. "In this case one must be accompanied ... It is done as a planned thing ... one reflects and talks ...with the manager or with the mentor" (interview quotation).

Learning on the job is not restricted to individual learning. On the contrary, teamwork is a key part of it. Our analysis strongly supports the idea that teamwork has a high strategic importance for Microsoft. It is defined as one of the seven success factors and the entire company is structured around teams. Microsoft even understands its strategic business units as teams, composed of different department teams, whose managers comprise several management teams. Apart from these well defined structures, a lot of teams work together across the borders of departments, business units and nations.

To accomplish complex tasks, individual competences that are spread throughout the entire organisation are sought out, and integrated in teams that work together for a relatively short time. "We have that again and again, that strategic topics are tackled by cross-functional teams which often commit themselves freely to work together" (interview quotation). This implies that project members can work together, and pursue a common task as virtual teams. Again the principle of personal responsibility is stressed, because "people here do what they themselves think they should do. And if they take over too much, it is expected from them that they raise their voice accordingly. The personal responsibility is there" (interview quotation).

Successful teamwork is evident in the competences defined in the CTK, especially the social competences. These comprise the ability to establish good work relations in the long term, and to know how to deal respectfully with others. In addition, successful teams are characterised by high team spirit: i.e., each team member assumes responsibility for the timing and the success of the entire team. Open communication, effective conflict management, and other factors strongly promote this.

On the one hand, the importance of particular competences as a prerequisite for success depends on the type of the project (thus the task). On the other hand, it depends on the role that the individual team member plays (e.g., the role of the project manager). 
Reversing this conclusion suggests that the absence of these competences can impair substantially the success of the team.

Teams occasionally need to discuss and reflect on their own level of development. For this purpose, Microsoft offers teams the opportunity to hire a coach who will assist them in creating a coaching environment on the team level. Teams often use the so-called off sites for reflection and discussion. An off site is a meeting of one or more days in which managers and/or employees meet away from the office "to discuss in order to find us as a team, to plan difficult topics, where we really take the time during a whole day" (interview quotation). Off sites enable the evaluation of, and reflection on, current content-related questions, and the team process itself. Additionally, teams have the option to undertake common trainings to improve cooperative behaviour or the analysis of problems.

Another learning forum is offered through learning teams, which are known as learning networks. These are "learning groups that cross departments and that after a Kick-off training are independently steered by the participants themselves" (interview quotation). Learning teams are intended to offer a stimulating environment, in which there occur self-assessment, feedback processes, and exchange of experience between the participating employees. Learning teams are completely handed over to the selforganising capacity of the members, Microsoft neither supplies topics nor controls the outcomes. Again, employees take over the responsibility for their own time and resources.

In summary, it can be said that learning in teams is integrated in the everyday work life. Moreover, teams seem to promote the personal development of technical and social competences to a high degree. Based on our analysis, we strongly support the proposition that teams positively affect individual competences.

\subsection{Evaluation of competence development}

Competence development can be assessed and adjusted through reflection. Microsoft applies several formalised evaluation procedures to assess individual and team competence and performance.

Individual performance evaluation. The evaluation of individual competence development takes place half-yearly, during the performance review. The work that has been carried out is compared to the businesses and development goals that were discussed and documented in the development review. At Microsoft, it is assumed that new or improved competences will show up in the job practice, because the competences were acquired consciously and goal-oriented. This means, that the existence of particular competences is inferred from the practical work activity. Likewise, improved action will be interpreted as competence development. Thus, competence evaluation is to be equated with performance evaluation, in which the goalsheet is the central instrument.

A system of grades from 2.5 to 5 describes the degree to which goals have been achieved. A grade of 2.5 is assigned at the lowest level, in the case where the employee "falls below performance standard and expectations of the job, demonstrates one or more performance deficits." Both the quantitative goals (business goals) and the qualitative goals (development goals) enter into the performance assessment. "There are surely goals which are difficult to measure and others like sales objectives are naturally easily to measure" (interview quotation). A grade of 4 indicates the complete fulfilment of all goals, and thus leaves enough space to recognise individual excellence, over and above 
the issues defined six months before. The sample questions on the competence card help to stimulate the discussion and are designed to assist the manager in the assessment of the relatively qualitative competence goals. Apart from that, feedback from colleagues and other managers can be an important source of information for the performance evaluation. Altogether "one gets a terribly good feeling for the grade" (interview quotation), which is the basis for salary increase and promotion (Hensche, 2001). Another advantage of this procedure is its transparency.

Team performance evaluation. The evaluation of teams consists of two parts. To stress the team responsibility as a whole, each team member's performance is judged equally against the degree to which business goals have been reached. In addition, there is an individual part of the performance evaluation, which examines whether or not the individual development goals have been realised. If the team reports to different managers, then the evaluation of the individual team members takes place in a joint conference. A suggestion for the employee in question is proposed by his or her respective manager, discussed, and compared with the grades of other employees at the same level.

The mutual evaluation of the team members, in the form of formalised feedback, does not exist. The only formal source of information is the organizational health index $(\mathrm{OHI})$, which contains the results of worldwide employee questioning. From the OHI, individual sub-indexes can be derived, which provide information about the team-internal climate, the satisfaction concerning cooperation with other teams, or the relationship between team and manager, and between team and customer. This information is accessible to managers, who are expected to initiate appropriate actions if problems become apparent.

Figure 2 Competence development process

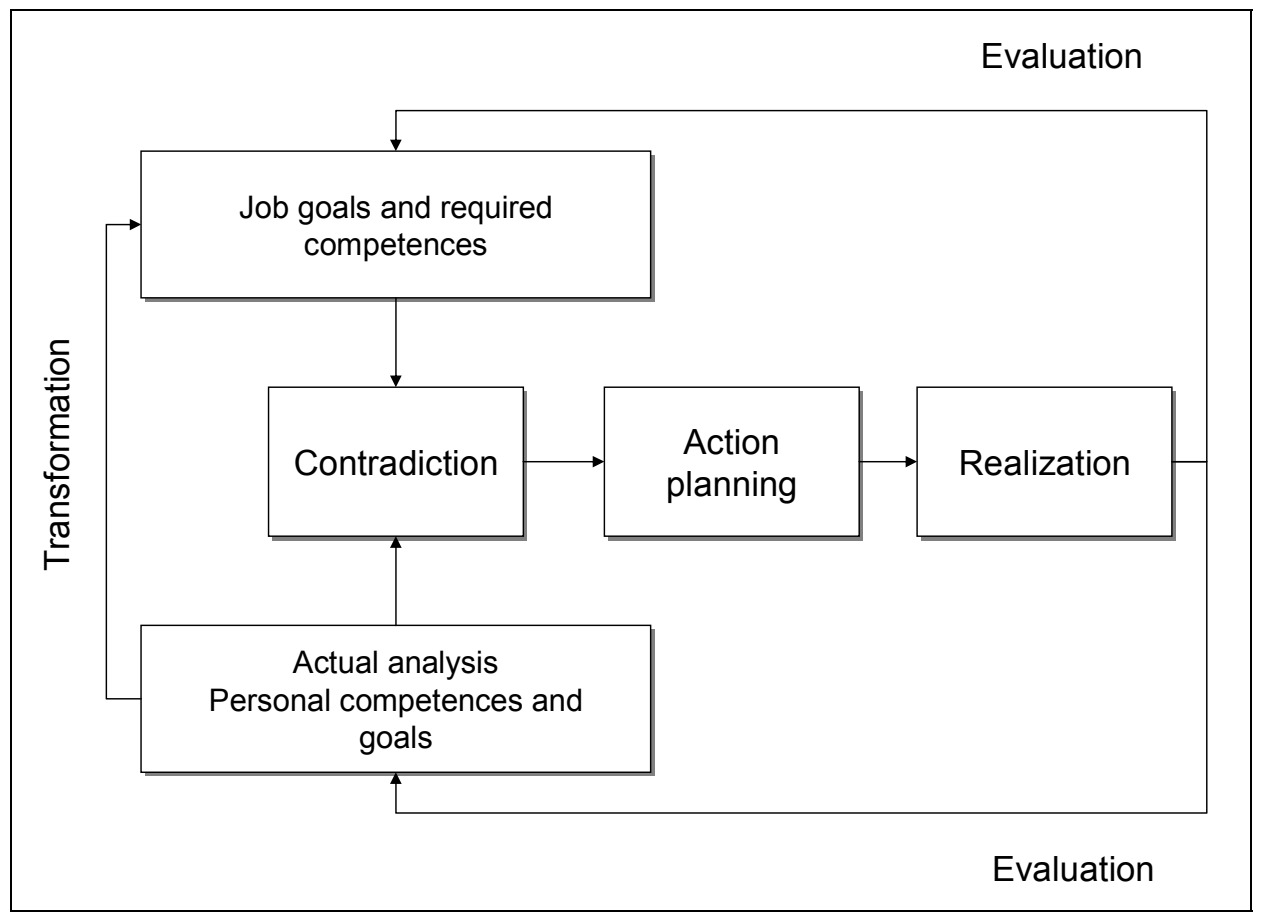


To sum up, the evaluation of competence development at Microsoft cannot be separated from the general performance review and, beyond that, it often serves to identify problems. Figure 2 describes how the phases of the competence development process are closely intertwined. Contradictions between competence expectancy and the actual state of competence, which become obvious through reflection, lead to active self-motivated planning and realisation of actions, the evaluation of which once again informs the actual competence and goal analysis. As far as the realisation of the competences improvement is concerned, teams play a predominant role, as almost $70 \%$ of the learning, and thus of the competences improvement, takes place on the job during teamwork, and is supported by learning teams.

\subsection{Case study conclusions}

In the previous section, we described the instruments Microsoft uses in the competence development process. It became clear that some of the instruments are cyclically assigned to particular phases, whereas others are used flexibly in different phases. The latter, such as the CTK, compose what we call tools (Senge et al., 1994). The CTK, e.g., serves various purposes at different stages of the process:

- $\quad$ First, it enables the identification of competences on four different qualitative levels. Using the questions in conversation can stimulate employees to report concrete examples from their work life that provide a basis on which self-assessment and outside assessment can be compared.

- Second, it supplies reference points for setting personal objectives, since the salary brackets and positions at Microsoft include clear requirements regarding the development of particular competences. The next stage in the competence development process depends substantially on the past role of the employee within the company, and the tasks associated with this role.

- Third, the competences specified in the CTK serve as an orientation for the kind of development action that is to be taken. For example, some competences have special trainings assigned.

- $\quad$ Finally, the CTK serves as a guideline for evaluating the agreed-upon goals during the semi-annual performance review.

Figure 3 systematises these relationships, and provides an overview of the methods and tools used. The instruments inside the circle display the flexible character of tools, whereas those placed around the circle are more strictly related to a particular process phase. Nonetheless, it depends on the individual's state of competence. Thus, the development review becomes, from the perspective of a young manager who trains his or her discussion leading competence, a for(u)m for realising objectives. Figure 3 shows that teams (team off-sites, teams on the job, learning teams) are an integral part of the individual competence development process as most of the work at Microsoft is inherently teamwork. 
Figure 3 Methods and tools of the competence development process

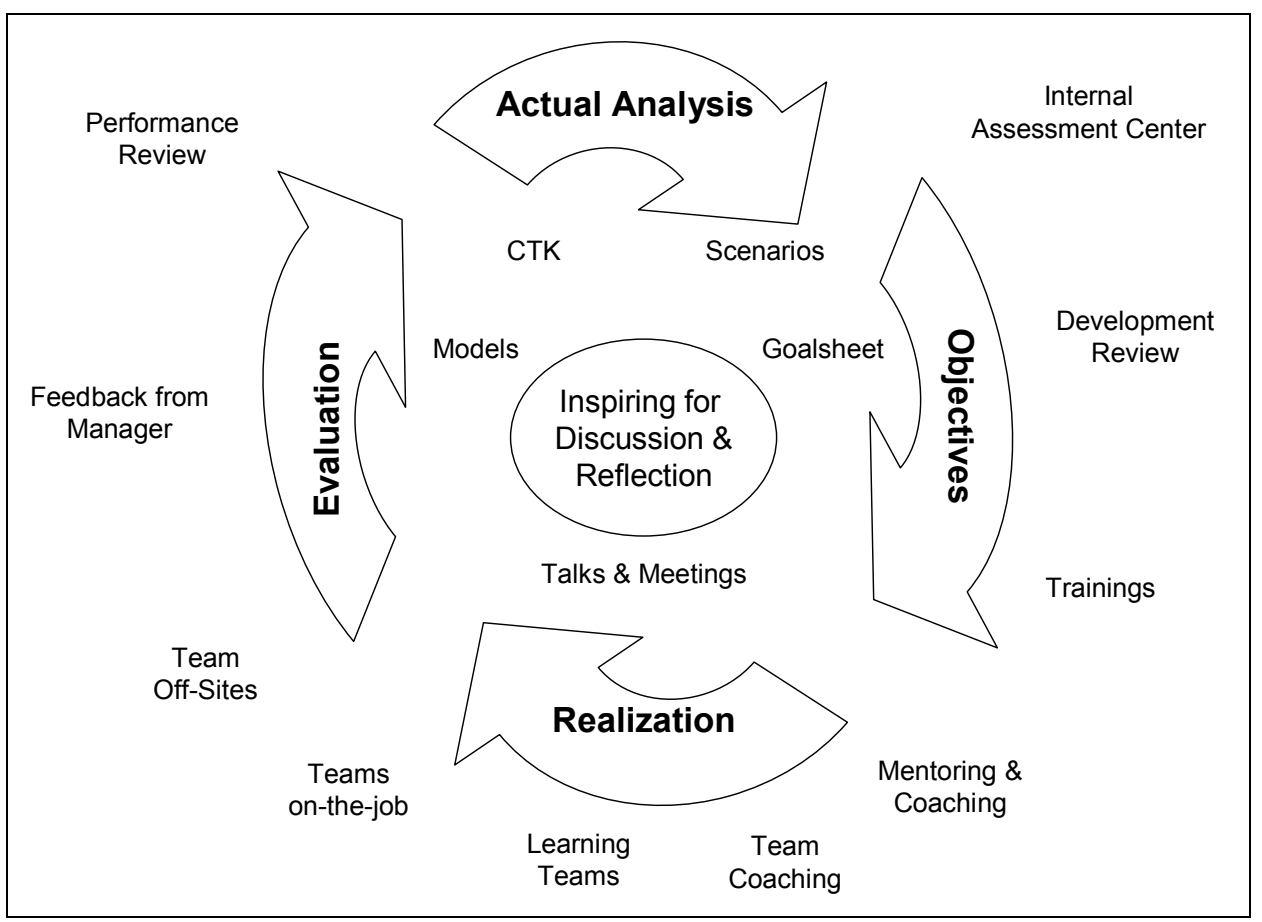

Our data analysis and interpretation were intended to provide a systematic and detailed overview of the competence development process at Microsoft Germany in order to create a common basis for judging the role and meaning of teams for competence development. In the following section, the findings will be discussed in relation to the theoretical underpinnings of the study.

\section{Discussion, limitations and direction for future research}

Organisational learning is a very important issue for Microsoft, which considers itself on the way to becoming a learning organisation in an internationally-orientated context (Argyris and Schön, 1978, 1996; Cusumano and Selby, 1996; Kolb, 1984; Senge, 1990). In addition, the success factors of the company can also be interpreted as organisational capabilities and/or competences (Barney, 1991), which permit coordinated, organised action in a complex, dynamic environment. For Microsoft, competences are first of all understood as individual goals and achievement-oriented capabilities, which are proved through action, and which need to be continually improved.

With regard to competence development, the human resource department and managers have mainly advisory functions. Instead, the self-responsibility of individuals and teams is emphasised, and self-organised actions are welcome. This points to an understanding of competence in the sense of internal conditions for particular situational actions which is similar to those of Erpenbeck and von Rosenstiel (2003). Teams are considered to foster and support individual competence development through learning teams, teams on the job, and team off-sites. Thus, they are an integral part of the 
individual competence development process by providing many different learning opportunities, as well as opportunities for discussion and reflection.

The for(u)ms for competence development clearly indicate a constructivist understanding of learning (von Glasersfeld, 1987; Luhmann 1990). This becomes especially obvious when we recall that employee and manager jointly undertake the analysis of the actual state of competence analysis, the identification of contradictions, and the setting of business and development goals. In realising these goals, most importance is attached to learning in the social context (Bandura, 1979). This means that teams, during the work process, and through the assumption of new tasks and roles. Jobnear learning is mainly supplemented by other learning forms like trainings, within certain financial and time limits, because training fulfilment is positively related to posttraining organisational commitment and motivation (Tannenbaum et al., 1991).

At Microsoft, teams are used as a combined learning and work form, and they serve both individual and organisational competence development. The results of these learning processes are evaluated by a competence-oriented performance review, which refers to those goals formulated at the beginning. The cross-comparison of self and foreign judgment, which is obtained by the feedback procedures, seems to have a positive influence on the further competence development process. This is mainly because the discovery of contradictions and problems, through these feedback mechanisms, leads directly to actions that concern future competence development.

Although the competence development process at Microsoft Germany has a positive impact, some limitations and restrictions apply. First, personal readiness and motivation to change and develop competences is required (Cannon-Bowers et al., 1998). "Someone, who is not ready there, does not get ahead" (interview quotation). When recruiting new employees, Microsoft does attempt to take into consideration a basic affinity for change and flexibility. Afterwards, the methods and processes themselves create consciousness of the necessity to change. However, the demanding requirements of everyday business life may themselves restrain and affect the recourse to and/or availability of particular time-intensive and cost-intensive learning forms. In the long run, employees need to take on responsibility for their own competence development.

Second, the transparency of the systems can create great pressure, as competences are developed and more responsibility is taken over. This pressure must be balanced against the achievement of personal development and growth. At Microsoft, consciousness of the necessity of crises and challenges for personal development is passed on through exchange of experience. Interestingly, the transparency of the evaluation systems may have a strong motivational effect.
"Some indicators show that altogether the organization is good, because of best employers etc., also in terms of business successes, the climate, how is worked here, how people exert themselves ... This drive of the people to push the company forward, this is really a great dynamic. This dynamic exists and people therefore show a lot of engagement and have much fun at work ... I am very proud, I really must admit, if I receive my good marks from the employees in such an environment with a high transparency, so that I am able to see: Hey, that is what I have reached!" (interview quotation)

Third, due to the dynamic nature of competences, the competence development process must be exposed to constant critical revision, despite all positive experiences. E.g., Microsoft regularly examines the appropriateness of its success factors and, if necessary, 
adds new competences to the CTK. In addition, Microsoft evaluates trainings and searches for new methods of competence development.

Fourth, generalisation is hardly possible based on this single case study. From this point of view, our study lacks a certain degree of external validity which means the degree to which findings can be generalised to other settings (Denzin and Lincoln, 1994) similar to Microsoft. However, it is important to note that this was not the intention of this exploratory and descriptive paper as we had the intention to analyse the competence development process at Microsoft as a unique case. Given the specific company's culture and environmental situation, neither the competence development process nor the team structures of Microsoft can be transferred easily to other organisations. Our aim was to explore and describe the roles teams can assume in the competence development process. This case study is located in the knowledge-intensive, complex, and dynamic environment of the IT industry. These environmental factors must be considered, as well as the fact that the 'status' of the Microsoft employees, as knowledge-workers, facilitates the consideration of competence during the performance evaluation. Because of that, our findings should rather be considered as suggestions or as a starting point for initiating a competence development process.

So far, no empirical study has analysed the role and contribution of teams in the competence development process of organisations. Apart from other industries, it would be worthwhile to examine whether the principles of competence development can also be applied to other organisational contexts. In addition, we lack detailed knowledge of how different contents of the process phases influence team performance and vice versa. Interesting questions for further research are: Do concrete goals inhibit creativity, or do they foster performance? How much training does a team need to excel? What forms of team-oriented performance evaluation influence further competence development, and in what ways?

Much has been said about the learning organisation, but few insights exist into whether and how teams really contribute to the development of organisational competence. The interfaces and connections between individual, team, and organisation are far from being understood well. Action research may be one suitable approach to examining these issues more closely, and to improving our knowledge of the role and importance of teams in competence development. If this paper has generated interest in such projects, then it has served its purpose.

\section{References}

Antoni, C.H. (Ed.) (1996) Gruppenarbeit in Unternehmen: Konzepte, Erfahrungen, Perspektiven, Beltz Psychologie Verlags-Union, Weinheim.

Argyris, C. and Schön, D.A. (1978) Organizational Learning: A Theory of Action Perspective, Addison Wesley, Reading, Mass.

Argyris, C. and Schön, D.A. (1996) Organizational Learning II: Theory, Method and Practice, Addison Wesley, Reading, Mass.

Baitsch, C. (1985) Kompetenzentwicklung und partizipative Arbeitsgestaltung: Eine hermeneutische Analyse bei Industriearbeitern in einer sich verändernden Arbeitssituation. Lang, Bern.

Bandura, A. (1979) Sozial-kognitive Lerntheorie, Klett-Cotta, Stuttgart.

Barney, J.B. (1991) 'Firm resources and sustained competitive advantage' Journal of Management, Vol. 17, No. 1, pp.99-120. 
Cannon-Bowers, J.A., Rhodenizer, L., Salas, E. and Bowers, C.A. (1998) 'A framework for understanding pre-practice conditions and their impact on learnin', Personnel Psychology, Vol. 51, No. 2, pp.291-320.

Chomsky, N. (1980) 'Rules and representations', Behavioral and Brain Sciences, Vol. 3, pp.1-61.

Cusumano, M.A. and Selby, R.W. (1996) Die Microsoft-Methode: Sieben Prinzipien, wie man ein Unternehmen an die Weltspitze bringt, Freiburg im Breisgau.

Eisenhardt, K. (1989) 'Building theories from case study research', Academy of Management Review, Vol. 14, pp.532-550.

Erpenbeck, J. (1997) Selbstgesteuertes, Selbstorganisiertes Lernen. In Arbeitsgemeinschaft Qualifikations-Entwicklungs-Management (Ed.): Kompetenzentwicklung 97: Berufliche Weiterbildung in der Transformation - Fakten und Visionen, Waxmann, Münster, pp.309-316.

Erpenbeck, J. and von Rosenstiel, L. (Eds.) (2003) Handbuch Kompetenzmessung: Erkennen, Verstehen und Bewerten von Kompetenzen in der betrieblichen, pädagogischen und psychologischen Praxis, Schäffer-Poeschel-Verlag, Stuttgart.

Foster, S.F., Heling, G.W.J., Tideman, B. and Remmé, J.H.M. (1995) Teams in Intelligent ProcessBased Organizations, Leidschendam.

French, W.L. and Bell, Jr., C.H. (1994) Organisationsentwicklung, 4th ed., Stuttgart und Wien, Bern.

Frese, M. and Zapf, D. (1994) 'Action as the core of work psychology: a German approach', in Triandis, H.C., Dunnette, M.D. and Hough, L.M. (Eds.): Handbook of Industrial and Organizational Psychology, 2nd ed., Vol. 4, pp.271-340, Consulting Psychologists Press, Palo Alto, CA.

Glaser, B. and Strauss, A. (1967) The Discovery of Grounded Theory: Strategies of Qualitative Research, Weidenfeld and Nicolson, London.

Greif, S. and Kurtz, H-J. (1998) Handbuch Selbstorganisiertes Lernen, 2nd ed., Verlag für Angewandte Psychologie, Göttingen.

Hacker, W. (1986) Arbeitspsychologie, Huber, Bern.

Hackman, J.R. and Oldham, G.R. (1980) Work Redesign, AddisonWesley, Reading, MA.

Hamann, P. and Freiling, J. (Eds.) (2000) Die Ressourcen und Kompetenzperspektive des Strategischen Managements, Wiesbaden.

Hensche, C. (2001) ,Kompetenz-Entwicklung und Karriere-Modelle im IT-Bereich' in Schwuchow, K. and Gutmann, J. (Eds.): Jahrbuch Personalentwicklung und Weiterbildung 2001/2002, pp.204-207, Luchterhand Verlag, Neuwied.

Jick, T.D. (1979) 'Mixing qualitative and quantitative methods: triangulation in action', in Van Maanen, J. (Ed.): Qualitative Methodology, pp.135-148, Sage, Beverly Hills.

Kepper, G. (1996) Qualitative Marktforschung: Methoden, Einsatzmöglichkeiten und Beurteilungskriterien, 2nd ed. rev., DUV, Dt. Univ.-Verl, Wiesbaden.

Kolb, D.A. (1984) Experimental Learning: Experience as the Source of Learning and Development, Prentice-Hall, Englewood Cliffs, NJ.

Lado, A., Boyd, N. and Wright, P. (1992) 'A competency-based model of sustainable competitive advantage: toward a conceptual integration', Journal of Management, Vol. 18, No. 1, pp.77-91.

Lee, T.W. (1999) Using Qualitative Methods in Organizational Research, Sage, Thousand Oaks, CA.

Luhmann, N. (1990) Soziologische Aufklärung/ 5. Konstruktivistische Perspektiven, Westdeutscher Verlag, Opladen.

Mathieu, J. E., Goodwin, G.F., Heffner, T.S., Salas, E. and Cannon-Bowers, J.A. (2000) 'The influence of shared mental models on team process and performance', Journal of Applied Psychology, Vol. 85, No. 2, pp.273-283. 
Mathieu, J.E., Heffner, T.S., Goodwin, G.F., Cannon-Bowers, J.A. and Salas, E. (2005) 'Scaling the quality of teammates' mental models: equifinality and normative comparisons', Journal of Organizational Behavior, Vol. 26, No. 1, pp.37-56.

Mayring, P. (1993) Einführung in die qualitative Sozialforschung: Eine Anleitung zu qualitativem Denken, 2nd ed., Deutscher Studien Verlag, Weinheim.

McClelland, D.C. (1973) 'Testing for competence rather than for intelligence', American Psychologist, Vol. 28, No. 1, pp.1-14.

McGrath, J.E. (1984) Groups: Interaction and performance, Prentice-Hall, Englewood-Cliffs, NJ.

Miles, M.B., and Huberman, A.M. (1994) Qualitative Data Analysis: an Expanded Sourcebook, 2nd ed., Sage, Beverly Hills.

Parker, G.M. (1990) Team Players and Teamwork: The New Competitive Business Strategy, Jossey-Bass, San Francisco, CA.

Piaget, J. (1948) The Moral Judgment of the Child, Free Press, Glencoe, IL.

Prahalad, C.K. and Hamel, G. (1990) 'The core competence of the corporation', Harvard Business Review, Vol. 68, pp.79-91.

Reynolds, M. and Vince, R. (2004) Organizing Reflection, Ashgate Publishing, Aldershot.

Sader, M. (1991) Psychologie der Gruppe Weinheim and München, Juventa.

Salas, E., Burke, C.S., and Cannon-Bowers, J.A. (2000) 'Teamwork: emerging principles', International Journal of Management Review, Vol. 2, No. 4, pp.339-356.

Seel, N.M. (1991) Weltwissen und mentale Modelle, Hogrefe, Göttingen.

Senge, P.M. (1990) The Fifth Discipline: The Art and Practice of the Learning Organization, Currency Doubleday, New York.

Senge, P.M. et al. (1994) The fifth discipline fieldbook: Strategies and tools for building a learning organization, Currency Doubleday. New York.

Straka, G.A. and Stöckl, M. (Eds.) (2001) Selbstgesteuertes Lernen und individuelles Wissensmanagement, Universität Bremen, Bremen.

Tannenbaum, S.I., Mathieu, J.E., Salas, E. and Cannon-Bowers, J.A. (1991) 'Meeting trainees' expectations: the influence of training fulfillment on the development of commitment, self-efficacy, and motivation', Journal of Applied Psychology, Vol. 76, No. 6, pp.759-769.

Unger, H. (2002) Organisationales Lernen durch Teams: Methode und Umsetzung eines teambasierten Projektmanagements, München and Mering.

von Glasersfeld, E. (1987) Wissen, Sprache und Wirklichkeit. Arbeiten zum radikalen Konstruktivismus, Vieweg, Braunschweig.

Vygotsky, L.S. (1978) Mind in Society, Harvard University Press, Cambridge, MA.

Weinert, F.E. (2001) 'Concept of competence: aA conceptual clarification', in Rychen, D.S. and Salganik, L.H. (Eds.): Defining and Selecting Key Competencies, pp.45-65, Hogrefe and Huber, Göttingen.

Wernerfelt, B. (1984) 'A resource-based view of the firm', Strategic Management Journal, Vol. 5, No. 2, pp.171-180.

Wheaton, A. (2002) Mitarbeitertraining und Partnering, available at www.muenchnerkreis.de/deut/020920/microsoft.htm (accessed on 20 September 2002).

White, R.W. (1959) 'Motivation reconsidered: the concept of competence', Psychological Review, Vol. 66, No. 5, pp.297-333.

Witte, E.H. and Davis, J.H. (1994) Understanding Group Behaviour, Vol. 1, Lawrence Erlbaum, Mahwah, NJ.

Yin, R.K. (1984) Case Study Research, Sage, Beverly Hills, CA. 